\title{
Review
}

\section{Preeclampsia Biomarkers - The quest goes on}

\author{
Brinderjeet Kaur ${ }^{1}$, Rateesh Sareen ${ }^{2 *}$ \\ ${ }^{1}$ Department of Obstetrics and Gynecology, Santokba Durlabhji Memorial Hospital and Research Center, Jaipur, India \\ ${ }^{2}$ Department of Pathology, Santokba Durlabhji Memorial Hospital and Research Center, Jaipur, India \\ * Corresponding author (E-mails:dr.bjkaur@gmail.com, [BK], drrateeshsareen@yahoo.co.in [RS])
}

\begin{abstract}
Preeclampsia (PE) is a multisystem disorder of pregnancy and a major cause of maternal morbidity and mortality worldwide. The disease is recently attributed to maternal endothelial dysfunction. The quest for ideal biomarker goes on. Pregnancyassociated plasma protein A (PAPP-A), Placental growth Factor (PLGF) and sFlt-1 (soluble fms-like tyrosine kinase-1) are the new biomarkers that hold promise for future. We present a short review on current biomarkers that would enable us to diagnose PE timely leading to reduced maternal morbidity and mortality, justifying the saying, ' a stitch in time saves nine'.
\end{abstract}

Key words- Preeclampsia, Biomarkers, PAPP-A, PLGF, Sflt

\section{Introduction}

The current decades have witnessed improved antenatal care but preeclampsia (PE) poses a serious complication of second half of Pregnancy with a frequency of 5-10\%. It is a leading cause of maternal morbidity which can lead to maternal death, fetal growth retardation, infant morbidity and mortality (Hoffman et al., 2011). Preeclampsia is defined as a systolic blood pressure $\geq 140 \mathrm{mmHg}$ or diastolic blood pressure $\geq 90 \mathrm{mmHg}$ on 2 occasions at least $4 \mathrm{hrs}$ apart after 20weeks gestation in women with a previously normal blood pressure or $\geq 160 \mathrm{mmHg}$ systolic or $\geq 110 \mathrm{mmHg}$ diastolic, and proteinuria $\geq 300 \mathrm{mg} / 24 \mathrm{hrs}$ or a Protein / creatinine ratio $\geq 0.3 \mathrm{mg} / \mathrm{dl}$ or a dipstick reading of $\geq 1+($ ACOG, 2013).

The early diagnosis of $\mathrm{PE}$ remains a challenge to modern obstetrician due to lack of specific marker or single test that is sensitive and specific enough for identification of high risk pregnancies for PE. The pathogenesis of preeclampsia is unclear (Lorentzen and Henriksen, 1998). Trophoblast cells and an accelerated maternal systemic response to trophoblastic tissue are the core stone in pathogenesis of preeclampsia (Sargent et al., 2003; Roberts and Hubel, 2009). In early pregnancy abnormal placentation occurs which leads to placental ischemia (Stage I). The ischemic placenta is thought to secrete soluble factors during the third trimester that in turn induces systemic endothelial dysfunction and the maternal syndrome of preeclampsia (Stage II) (Redman and Sargent, 2005). In normal pregnancy there is trophoblastic invasion of the spiral arteries in the decidual and myometrial segments of the placental bed, whereas in preeclampsia such physiological adaptation does not occur severely compromising their ability to deliver maternal blood in the intervillous space. The diagnosis of PE relies on medical and obstetrics history, markers like maternal Serum pregnancy associated Plasma protein -A (PAPP-A) and Placental growth Factor (PLGF) at 11-13 weeks, uterine artery pulsatility Index (PI) and Mean arterial Pressure (MAP) (Wright et al., 2012; Akolekar et al., 2013). In this article we focus on biomarkers for PE screening.

Maternal serum PAPP-A and PlGF are two biochemical markers that have been investigated extensively and have shown promising results in the early prediction of PE at 11-13 weeks' gestation, and are done on automated machines that provide reproducible results within 30-40 min of sampling (Wright et al., 2014). Pregnancy-associated plasma protein A (PAPP-A) is a peptidase produced by syncitiotrophoblast with hydrolytic activity for insulin-like growth factor binding proteins (Kleinrouweler et al., 2012). These regulate insulin growth factors known to be important for implantation, for trophoblast invasion of maternal decidua and for placental growth. It is released into the maternal circulation where it binds the eosinophil major binding protein, an inhibitor of its proteolytic activity (Poon and Nicolaides, 2014). Decreased levels of PAPP-A in the first trimester have been associated with increased risk of adverse pregnancy outcomes, including preeclampsia.

Serum levels of PGF and sFlt-1 (soluble fms-like tyrosine kinase-1, also known as soluble VEGF receptor-1) are altered in women with preeclampsia. Maternal serum levels of sFlt-1 are higher and PGF lower in women presenting with preeclampsia. Soluble fms-like tyrosine kinase-1 (sFlt-1 or sVEGFR-1) is a tyrosine kinase protein with antiangiogenic properties. A non-membrane associated splice variant of VEGF receptor 1 (Flt-1), sFlt-1 binds the angiogenic factors VEGF (vascular endothelial growth factor) and PlGF (placental growth factor), reducing blood vessel growth through reduction of free VEGF and PIGF concentrations (Khalil et al., 2008). In humans, sFlt-1 is important in the regulation of blood vessel formation in diverse tissues, including the kidneys, cornea, and uterus (Ambati et al., 2006; Luft, 2014). Abnormally high levels of sFlt-1 have been implicated in the pathogenesis of preeclampsia (Maynard et al., 2003). In preeclamptic patients, this arterial transformation is incomplete, as cytotrophoblasts fail to completely switch their adhesion molecule expression pattern to an endothelial form. The balance of pro- and anti-angiogenic factors and their receptors, including VEGF-A, PIGF, Flt1, and sFlt1, is thought to mediate this process (Maynard et al., 2003).

PlGF and sFlt-1 concentrations measured by immunoassay in maternal blood improve the prognostic 
possibilities in preeclampsia, which is typically diagnosed solely on the basis of clinical symptoms, proteinuria, and uterine artery Doppler velocimetry (Thadhani et al., 2004; Hirashima et al., 2005). Notably, increases in sFlt-1 and decreases in PIGF and VEGF can be detected at least five weeks before the onset of preeclamptic symptoms, potentially facilitating earlier diagnosis and treatment (Levine et al., 2004). sFlt-1 elevation is also associated with other obstetric conditions such as non-preeclampsic interuterine growth retardation of the fetus, limiting its use as a discriminatory biomarker for preeclampsia (Bersinger et al., 2003). Additionally, sensitivity and specificity of sFlt-1 testing is generally considered too low to enable it to serve as an effective predictor of preeclampsia (Stepan et al., 2004). However, PE is associated with reduced PIGF production and these reduced levels precede the clinical onset of the disease and are evident from first and second trimester of pregnancy (Polliotti et al., 2003; Krauss et al., 2004; Erez et al., 2008; Crispi et al., 2008):

It is extremely important that while performing the biochemical assay appropriate adjustments for maternal age , pregnancy, instrument and reagent are made and the results expressed as multiple of the expected median (MoM) of the normal (Kagan et al., 2008). MoM values of PAPP-A and PIGF are reduced at 11-13 weeks in pregnancy associated with PE. Serum sFlt-1 increases with gestational age and maternal age and decreases with maternal weight; it is increased in women of Afro-Caribbean racial origin and in pregnancies conceived by IVF and is lower in parous than nulliparous women (Lai et al., 2014).

\section{Conclusion}

The screening for early onset of PE can be successfully done in first trimester pregnancy with the help of new biomarkers alongside the history and biophysical markers. This would enable detection of cases that require prophylactic intervention. Prospective studies are underway to ascertain the predictive capabilities of these markers, till then the quest for single specific screening marker go on.

\section{References}

Akolekar, R., Syngelaki, A., Poon, L., Wright, D., and Nicolaides, K.H. (2013). Competing risks model in early screening for preeclampsia by biophysical and biochemical markers. Fetal Diagnosis and Therapy, 33, $8-15$.

Ambati, B.K., Nozaki, M., Singh, N., Takeda, A., Jani, P.D., Suthar, T., Albuquerque, R.J., Richter, E., Sakurai, E., Newcomb, M.T., Kleinman, M.E., Caldwell, R.B., Lin, Q., Ogura, Y., Orecchia, A., Samuelson, D.A., Agnew, D.W., St Leger, J., Green, W.R., Mahasreshti, P.J., Curiel, D.T., Kwan, D., Marsh, H., Ikeda, S., Leiper, L.J., Collinson, J.M., Bogdanovich, S., Khurana, T.S., Shibuya, M., Baldwin, M.E., Ferrara, N., Gerber, H.P., De Falco, S., Witta, J., Baffi, J.Z., Raisler, B.J., and Ambati, J. (2006). "Corneal avascularity is due to soluble VEGF receptor-1. Nature, 443 (7114), 9937.

American College of Obstetricians and Gynecologists. (2013). Hypertension in pregnancy. Report of the American College of Obstetricians and Gynecologists'task force on hypertension in pregnancy. Obstetrics and gynecology, 122(5), 1122.
Bersinger, N.A., Smárason, A.K., Muttukrishna, S., Groome, N.P., and Redman, C.W. (2003). Women with preeclampsia have increased serum levels of pregnancyassociated plasma protein A (PAPP-A), inhibin A, activin A and soluble E-selectin. Hypertens Pregnancy, 22, 45-55.

Crispi, F., Llurba, E., Domínguez, C., Martín-Gallán, P., Cabero, L., and Gratacós, E. (2008). Predictive value of angiogenic factors and uterine artery Doppler for earlyversus late-onset preeclampsia and intrauterine growth restriction. Ultrasound in Obstetrics \& Gynecology, 31, 303-309.

Erez, O., Romero, R., Espinoza, J., Fu, W., Todem, D., Kusanovic, J.P., Gotsch, F., Edwin, S., Nien, J.K., Chaiworapongsa, T., Mittal, P., Mazaki-Tovi, S., Than, N.G., Gomez, R., Hassan, S.S. (2008). The change in concentrations of angiogenic and anti-angiogenic factors in maternal plasma between the first and second trimesters in risk assessment for the subsequent development of preeclampsia and small-for-gestational age. Journal of Maternal-Fetal and Neonatal Medicine, $21,279-287$.

Hirashima, C., Ohkuchi, A., Arai, F., Takahashi, K., Suzuki, H., Watanabe, T., Kario, K., Matsubara, S., and Suzuki, M. (2005). Establishing reference values for both total soluble Fms-like tyrosine kinase 1 and free placental growth factor in pregnant women. Hypertension Research, 28(9), 727-732.

Hoffman, B., Horsager, R., Roberts, S., Rogers, V., and Worley, K. (2011). Williams Obstetrics $23^{\text {rd }}$ Edition. New York, USA: McGraw-Hill Professional Publishing, Hypertension in pregnancy. Pp 709-715.

Kagan, K.O., Wright, D., Spencer, K., Molina, F.S., Nicolaides, K.H. 2008. First trimesterscreening for trisomy 21 by free beta-human chorionic gonadotropin and pregnancy-associated plasma protein-A: impact of maternal an pregnancy characteristics. Ultrasound in Obstetrics \& Gynecology, 31,493-502.

Khalil, A., Muttukrishna, S., Harrington, K., and Jauniaux, E. (2008). Effect of antihypertensive therapy with alpha methyldopa on levels of angiogenic factors in pregnancies with hypertensive disorders. PLOS One, 3(7): e2766.

Kleinrouweler, C.E., Wiegerinck, M.M., Ris-Stalpers, C., Bossuyt, P.M., van der Post, J,A.,von Dadelszen, P., Mol, B.W., and Pajkrt, E. (2012). Accuracy of circulating placental growth factor, vascular endothelial growth factor, soluble fms-like tyrosine kinase 1 and soluble endoglin in the prediction of pre-eclampsia: a systematic review and meta-analysis. BJOG, 119(7), 778-787.

Krauss, T., Pauer, H.U., and Augustin, H.G. (2004). Prospective analysis of placenta growth factor (PIGF) concentrations in the plasma of women with normal pregnancy and pregnancies complicated by preeclampsia. Hypertens Pregnancy, 23, 101-111.

Lai, J., Garcia-Tizon Larroca, S., Peeva, G., Poon, L.C., Wright, D., Nicolaides, K.H. (2014). Competing risks model in screening for preeclampsia by serum placental growth factor and soluble fms-like tyrosine kinase-1 at 30-33 weeks' gestation. Fetal Diagnosis and Therapy, 35(4):240-248. 
Levine, R.J., Maynard, S.E., Qian, C., Lim, K.H., England, L.J., Yu, K.F., Schisterman, E.F., Thadhani, R., Sachs, B.P., Epstein, F.H., Sibai, B.M., Sukhatme, V.P., and Karumanchi, S.A. (2004). Circulating angiogenic factors and the risk of preeclampsia. The New England Journal of Medicine, 350(7), 672-683.

Lorentzen, B., and Henriksen, T. (1998). Plasma lipids and vascular dysfunction in preeclampsia. Seminars in Reproductive Endocrinology, 16(1), 33-39.

Luft, F.C. (2014). Soluble fms-like tyrosine kinase-1 and atherosclerosis in chronic kidney disease. Kidney International, 85(2), 238-240.

Maynard, S.E., Min, J.Y., Merchan, J., Lim, K.H., Li, J., Mondal, S., Libermann, T.A., Morgan, J.P., Sellke, F.W., Stillman, I.E., Epstein, F.H., Sukhatme, V.P., and Karumanchi, S.A. (2003). Excess placental soluble fmslike tyrosine kinase 1 (sFlt1) may contribute to endothelial dysfunction, hypertension, and proteinuria in preeclampsia. The Journal of Clinical Investigation, 111(5), 649-658.

Polliotti, B.M., Fry, A.G., Saller, D.N., Mooney, R.A., Cox, C., Miller, R.K. (2003). Second-trimester maternal serum placental growth factor and vascular endothelial growth factor for predicting severe, early-onset preeclampsia. Obstetrics \& Gynecology, 101, 1266-1274.

Poon, L.C, and Nicolaides, K.H. (2014). First-trimester maternal factors and biomarker screening for preeclampsia. Prenatal Diagnosis, 34, 618-627.
Redman, C.W., and Sargent, I.L. (2005). Latest advances in understanding preeclampsia. Science, 308(5728),15921594.

Roberts, J.M., and Hubel, C.A. (2009). The two stage model of preeclampsia: variations on the theme. Placenta, 30, 32-37.

Sargent, I.L., Germain, S.J., Sacks, G.P., Kumar, S., and Redman, C.W. (2003). Trophoblast deportation and the maternal inflammatory response in pre-eclampsia. Journal of reproductive immunology, 59(2), 153-160.

Stepan, H., Geide, A., and Faber, R. (2004). Soluble fms-like tyrosine kinase 1. The New England Journal of Medicine, 351(21), 2241-2242.

Thadhani, R., Mutter, W.P., Wolf, M., Levine, R.J., Taylor, R.N., Sukhatme, V.P., Ecker, J., and Karumanchi, S.A. (2004). "First trimester placental growth factor and soluble fms-like tyrosine kinase 1 and risk for preeclampsia. The Journal of Clinical Endocrinology and Metabolism, 89(2), 770-775.

Wright, D., Akolekar, R., Syngelaki, A., Poon, L.C., and Nicolaides, K.H. (2012). A competing risks model in early screening for preeclampsia. Fetal Diagnosis and Therapy, 32, 171-178.

Wright, D., Syngelaki, A., Bradbury, I., Akolekar, R., and Nicolaides, K.H. (2014). First-trimester screening for trisomies 21,18 and 13 by ultrasound and biochemical testing. Fetal Diagnosis and Therapy, 35, 118-126. 